\title{
Conferências nacionais como interfaces socioestatais: seus usos e papéis na perspectiva de gestores federais
}

Clóvis Henrique Leite de Souza e Roberto Rocha Coelho Pires

A multiplicação de experiências de participação social no Brasil foi acompanhada por um movimento na literatura especializada que se voltou para compreendêlas, privilegiando a perspectiva da sociedade civil. Em grande parte, os trabalhos sobre instituições participativas enfatizaram a ótica dos movimentos sociais, das organizações civis e de outros atores não governamentais, que passaram a atuar em fóruns e instâncias formalizados de interação com o Estado. Inicialmente, ressaltando os benefícios da conquista de espaços de participação, em seguida, observando com ceticismo as dificuldades de concretização de ideais democráticos e, posteriormente, delineando distintas estratégias de avaliação. Como consequência desse itinerário, até o momento, pouco se considerou a perspectiva dos gestores públicos e outros agentes burocráticos envolvidos na implementação de políticas que incorporam a interação com a sociedade em suas práticas.

O objetivo deste trabalho é fazer uma análise exploratória das percepções, motivações e justificativas dadas por gerentes de programas federais para a utilização 
de mecanismos de participação social. Em particular, buscamos compreender os usos, papéis e sentidos atribuídos por esses atores às conferências nacionais. Como atores burocráticos percebem a incidência de processos participativos (i.e. conferências) sobre a gestão de programas e ações sob sua responsabilidade? Em que medida as visões e sentidos atribuídos por tais agentes convergem com os objetivos formalmente estabelecidos para os processos conferenciais?

Para abordar tais questões, integramos estudos a respeito dos objetivos declarados nos atos normativos desses mecanismos de participação (SouZA, 2012) e a respeito das múltiplas formas de relação entre Estado e sociedade em âmbito nacional (PIRES E VAZ, 2012). Utilizamos dados oriundos de registros administrativos de avaliação dos programas federais que compuseram o Plano Plurianual 2008-2011 e contrastamos com informações obtidas em regimentos de conferências nacionais realizadas entre 2003 e 2010.

De início, poderíamos esperar coincidência entre os papéis almejados no momento de concepção das conferências e os papéis desempenhados por esses mecanismos de participação social na gestão de programas, afinal, em ambos os casos, os declarantes envolvem atores do próprio governo federal. Há, sim, muita concordância, mas os dados revelam distintos usos, a depender das áreas de políticas públicas analisadas. Também chama atenção a baixa frequência de utilização de conferências, quando comparadas com outros mecanismos de participação utilizados pelos programas federais. Mesmo que tenha havido ampliação temática e intensa mobilização, os responsáveis pelos programas federais têm relatado baixo uso da conferência como forma de interação com a sociedade. Isso pode sinalizar dificuldades de incidência na gestão pública, seja pela natureza e forma de funcionamento das conferências, seja pelos múltiplos entendimentos sobre seu papel.

A pesquisa aqui apresentada teve mais a intenção de conhecer a multiplicidade desses entendimentos para, em estudos futuros, investigar a percepção dos gestores federais a respeito dos desafios da gestão pública participativa. Torna-se relevante a visão dos sujeitos presentes na estrutura do Estado, para compreender suas concepções sobre as formas de relação com a sociedade. Essa perspectiva, até então pouco explorada, faz-se necessária quando entra em pauta a discussão da efetividade das instituições participativas (PIRES , 2011). Afinal, compreender como os gestores públicos justificam as formas de relação com a sociedade é elemento de análise importante para investigar os usos e os papéis que assumem tais mecanismos.

Este artigo focaliza as conferências como interfaces socioestatais e busca conhecer a diversidade de visões a seu respeito. Iniciamos com uma breve apresentação da lente analítica que utilizamos no trabalho - o conceito de interfaces socioestatais -, apontando seus potenciais ganhos para a reflexão sobre as formas de atuação e sentidos atribuídos por sujeitos estatais aos processos participativos. Em seguida, descrevemos as fontes de dados utilizadas e a estratégia metodológica que orientou a análise. A partir daí, apresentamos as conferências nacionais como interfaces e os usos e papéis atribuídos a elas pelos gerentes de programas federais em desenvolvimento no período de 2009 e 2010. Por fim, questionamo-nos sobre as consequências do baixo uso das conferências e da multiplicidade de visões sobre seus papéis para a incidência na gestão pública. 
Para além da participação: sujeitos estatais em interface com sujeitos sociais

Diante de conjunto tão diverso de áreas de políticas públicas, de atores sociais e atores governamentais, é intuitiva a percepção de que haverá diversidade de formas de relação entre Estado e sociedade. Para explicar tal variedade, poderíamos elencar fatores como grau de institucionalização da política, densidade organizativa do setor social, disputa de projetos políticos, entre outros. No entanto, não pretendemos traçar aqui o perfil das relações Estado-sociedade nesta ou naquela área de política pública, muito menos apresentar razões para tais características. Assim como Pires e Vaz (2012), queremos ressaltar essa diversidade e questionar se a noção de participação é capaz de abranger distintas formas de relação entre Estado e sociedade.

Vinculada a ideais de soberania popular, a noção de participação emergiu na teoria democrática, no decorrer do século XX, para fazer frente a visões que restringiam a democracia aos procedimentos eleitorais. Para as correntes teóricas ortodoxas, a participação tinha pouca relevância e ocupava lugar de destaque apenas quanto aos perigos relacionados à estabilidade dos sistemas políticos (Pateman, 1992). O surgimento de um pensamento heterodoxo, no que diz respeito ao procedimentalismo democrático, adveio com as perspectivas teóricas da deliberação e do espaço público que ampliaram a noção de participação (Avritzer, 1994; 1997; 2002; Santos e AvritZer, 2002).

Mesmo quando se reconhece que a "participação abrange um universo diferenciado de manifestações empíricas, e [que] sempre haverá dificuldades na sistematização de todo seu repertório nas democracias contemporâneas" (Avelar, 2007, p. 265), a noção de participação é permeada com a ideia de "exercício coletivo do poder político" (Santos e Avritzer, 2002, p. 53). Seja pela via teórica que enfatiza a deliberação pública ou por aquela que investiga a ação coletiva, as reflexões desenvolvidas a respeito da participação tendem

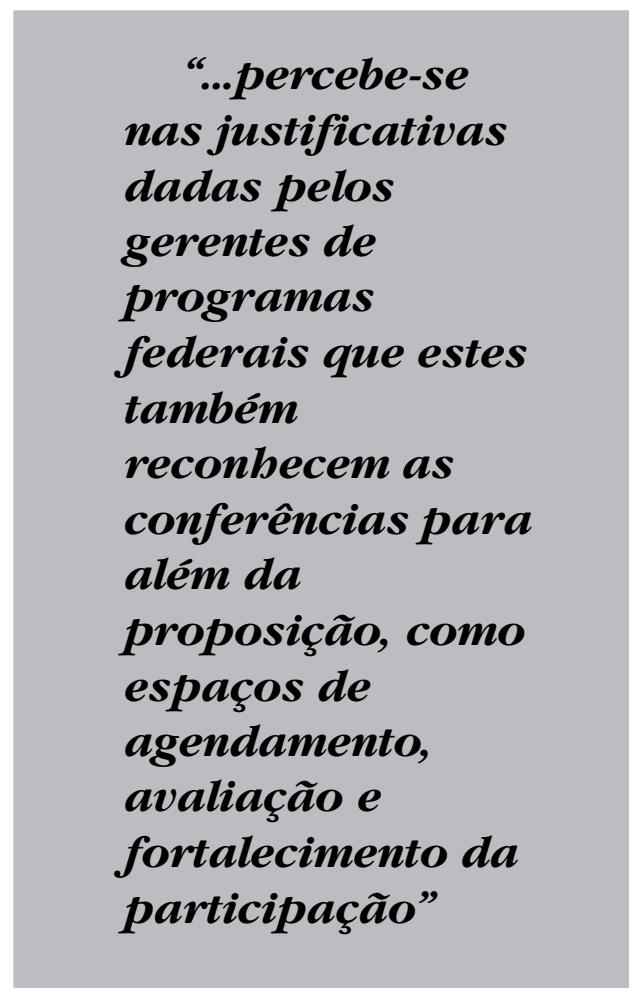

a ressaltar o caráter coletivo do processo, privilegiando o olhar de atores sociais.

Acreditamos que esse entendimento é fruto de concepções legítimas e muito bem fundamentadas, até pelos contextos histórico, político e intelectual em que emergiram as teorias contra-hegemônicas de democracia. No entanto, quando se percebe o caminho que tomou o processo de 
redemocratização brasileiro, em particular com a emergência de novas instituições que incorporam o diálogo com a sociedade, é pertinente questionar se a lente analítica da participação não é demasiadamente restritiva.

Considerando o "grau de institucionalização e capilaridade territorial dos arranjos participativos, bem como o fato de a participação ser uma feição institucional do Estado no Brasil" (Lavalle, 2011, p. 17), vale indagar se a participação entendida como expressão do exercício coletivo do poder político é chave interpretativa suficiente para compreender as distintas formas de interação do Estado com a sociedade. Se for suficiente, por que as pesquisas sobre participação concentraram-se até o momento em orçamentos participativos, conselhos e conferências de políticas públicas, e quase ignoraram, por exemplo, consultas públicas, audiências e ouvidorias?

Em nosso entendimento, tanto o direcionamento do olhar para a perspectiva de movimentos sociais e organizações civis como o enquadramento analítico para a ação coletiva, implícito na noção de participação, têm limitado a análise a respeito das distintas formas de relação entre o Estado e a sociedade. E mesmo trabalhos que reconhecem múltiplos repertórios de interação (Abers, Serafim e TAtagiBa, 2011) tendem a assumir a participação institucionalizada em uma perspectiva de ação coletiva, que acaba por aproximar a análise da visão de atores sociais, mesmo que a fronteira entre Estado e sociedade seja questionada. Por isso, observando a multiplicidade nas relações Estado-sociedade, percebemos a necessidade de uma nova lente analítica.

Nesse sentido, parece adequada a retomada que Vera (2006), Lavalle e Vera (2010) e Hevia e Vera (2010, p. 61) fazem da noção de interface, entendida como "espaço de intercâmbio e conflito em que certos atores se relacionam de forma intencional e não causal". Os autores desenvolvem $^{1}$, a partir daí, a ideia de interface socioestatal como "um dos possíveis espaços de intercâmbio, sendo composta por sujeitos sociais e sujeitos estatais" com diferentes intenções e papéis atribuídos².

O conceito de interface socioestatal permite, portanto, duas ampliações de escopo analítico em relação à forma como a literatura tem tratado os espaços institucionalizados de participação. A primeira diz respeito à percepção de formas de relação entre Estado e sociedade que vão além da participação de atores sociais em fóruns públicos, incluindo também interações presenciais ou não presenciais entre sujeitos sociais individuais e coletivos, de maneira permanente e regular ou esporádica e eventual; pois interfaces socioestatais se referem tanto a relações com fundamento legal quanto a interações $a d$ hoc. A segunda ampliação se dá à medida que se reconhece que tão importante quanto o envolvimento de sujeitos sociais é o envolvimento de sujeitos estatais.

Assim, uma interface socioestatal se abre em pelo menos duas distintas perspectivas: a do ator estatal e a do ator social. Em cada uma delas, o valor, o sentido e a função das interações socioestatais podem ser distintos, dado que o ponto, a partir do qual as relações são avaliadas, é de natureza diversa. Tal reconhecimento, embora possa parecer trivial, tem o potencial de nos permitir enxergar a perspectiva do ator estatal sobre os processos participativos, contrabalanceando a forte tendência da literatura de privilegiar o ponto de vista da sociedade civil.

Há relevância na ideia de interface socioestatal, pois as relações entre Estado e sociedade não se restringem às ações 
coletivas, nem aos mecanismos institucionalizados, mas, sim, encobrem uma variedade maior de formas de interação. Em segundo lugar, e talvez ainda mais relevante para os propósitos da presente análise, a noção de interface reconhece a possível diferenciação de perspectivas de sujeitos sociais e sujeitos estatais sobre os seus próprios encontros. Assim, chama a atenção para a intencionalidade desses sujeitos ao se relacionarem, isto é, aos sentidos, funções e papéis que atribuem ao esforço de interação. Ainda que possam ser eventuais, tais interações não seriam fortuitas, mas reveladoras do encontro das distintas perspectivas e intencionalidades (seja de intercâmbio ou de conflito) de atores sociais e estatais.

\section{Organização dos dados e estratégia de análise}

A noção de interface socioestatal possibilita o reconhecimento da multiplicidade de visões dos sujeitos envolvidos (sociais e estatais) nos encontros entre Estado e sociedade. Diante de tal possibilidade, a presente análise se propõe a identificar os sentidos, usos e papéis que os gestores públicos atribuem às conferências nacionais e compreender em que medida tais percepções convergem ou se diferenciam em relação aos objetivos formalmente estabelecidos. A estratégia analítica adotada baseia-se no contraste entre os objetivos e finalidades formalmente declarados nos atos normativos das conferências nacionais e as percepções declaradas pelos gestores públicos quanto ao papel desempenhado pelas conferências na gestão e implementação dos programas sob sua responsabilidade.

De um lado, as informações relativas à percepção dos gestores sobre os sentidos, usos e papéis das conferências são oriundas do módulo de avaliação de programas do Sistema de Informações Gerenciais e de Planejamento (Sigplan) do Ministério do Planejamento, Orçamento e Gestão ${ }^{3}$. Para cada programa federal, integrante do Plano Plurianual (PPA), há um gerente responsável pela alimentação do sistema com informações relativas ao desempenho de seu programa. No momento da avaliação, cada gerente respondeu a seguinte questão: "O Programa possui mecanismos que promovem a participação social?”. Quando a resposta foi afirmativa, questionou-se sobre o tipo de mecanismo utilizado, sendo dadas as seguintes opções: ouvidoria, audiência pública, consulta pública, reunião com grupos de interesse, discussão em conselho setorial, discussão em conferências e outros (Pires e VAz, 2012).

A discussão em conferências foi uma categoria disponibilizada somente na avaliação dos programas do PPA para os anos 2009 e 2010; por isso, apenas as respostas dos 434 programas ${ }^{4}$ realizados nesses anos puderam ser aqui analisadas. Além de dizer se o programa possuía ou não mecanismo de promoção da participação social, os gerentes deveriam explicar como tal mecanismo era utilizado. Foram essas explicações e justificativas, relativas ao uso das conferências nacionais, que geraram informações para as análises. Cabe mencionar que a opção foi pelo anonimato dos programas, diante $\mathrm{da}$ possibilidade de fácil identificação de seus gerentes. Assim, quando necessário, as respostas foram ajustadas para evitar a identificação.

De outro lado, as informações referentes aos objetivos formalmente declarados das conferências nacionais foram sistematizadas a partir dos atos normativos a elas associados. Foram utilizadas leis, decretos, 
portarias ministeriais ou interministeriais, resoluções de conselhos e, em particular, os atos que instituíram os regimentos dos processos participativos, pois especificavam os objetivos das conferências nacionais.

Os objetivos constantes nos atos normativos foram extraídos dos documentos-fonte, organizados em categorias e analisados. Após a compilação e a identificação de ideias centrais em cada objetivo, o processo de agrupamento por semelhança permitiu a criação de categoriassíntese. Tal como definido em Souza (2012), tais categorias de objetivos incluem: a) "agendamento", quando se referem à difusão de ideias e à afirmação de compromissos; b) "avaliação", quando estão em foco ações de diagnóstico de uma situação ou avaliação de políticas; c) "participação", quando falam em ampliação ou fortalecimento de espaços participativos na gestão de políticas públicas; e d) "proposição", quando trazem aspectos de formulação de estratégias ou políticas. Das 74 conferências nacionais ocorridas entre 2003 e 2010, foram encontrados documentos que revelaram os objetivos de 68 processos conferenciais ${ }^{5}$. Esse foi o universo de análise que, quando pertinente, foi desagregado nos processos realizados em 2009 e 2010, combinando com os dados dos programas federais.

Para que as comparações entre as percepções dos gestores públicos sobre os papéis e usos das conferências e as suas finalidades e objetivos formalmente declarados fossem possíveis, os dados foram organizados tendo como base os programas federais e agregados em áreas temáticas de políticas públicas. Revisitamos as classes temáticas já utilizadas em Pires e Vaz (2012) e Alencar et al. (2012) e chegamos à tipologia descrita a seguir. Os programas governamentais foram classificados, considerando seus nomes e finalidades, nas seguintes categorias:

- Desenvolvimento econômico - ações de apoio, fomento, regulação e financiamento voltadas ao setor produtivo, à organização do mercado e ao crescimento econômico;

- Infraestrutura e recursos naturais - ações voltadas para o desenvolvimento de condições materiais nas diversas áreas e à preservação do meio ambiente;

- Políticas sociais - ações voltadas para a organização e provisão de bens e serviços públicos destinados a promover condições e oportunidades de vida digna para a população;

- Garantia de direitos - ações com finalidade de efetivar direitos e prover oportunidades a grupos sociais historicamente excluídos.

Os programas que não foram desenvolvidos pelo Executivo foram agrupados na categoria "outros poderes". Os programas destinados a atuar como suporte e subsídio à gestão das demais atividades do governo foram reunidos na categoria "apoio à gestão".

Cabe ressaltar que nesta pesquisa foram utilizados dados oriundos dos registros administrativos de avaliação dos programas federais desenvolvidos em 2009 e 2010, pois apenas nesses anos o sistema de avaliação do Plano Plurianual incorporou as conferências como uma das possibilidades de interface socioestatal, ou, nos termos do questionário, como um dos mecanismos de promoção da participação social. A limitação temporal da análise é relativizada quando percebemos que esses dois anos são representativos da realização de conferências nacionais entre 2003 e 2010 , tendo em vista que foram realizados 74 processos no período, média de nove por ano, e que em 2009 foram realizados 13 e em 2010 manteve-se a média. 
Dado o corte temporal imposto pela existência de dados, é necessário apontar que as conferências nacionais são realizadas com diferentes periodicidades. Há processos realizados anualmente, bienalmente, trienalmente e quatrienalmente. Dessa forma, poderíamos deparar-nos com outra limitação da análise, pois programas vinculados a áreas que não realizaram conferências no período não informariam o uso dessas interfaces. No entanto, não é isso que se verifica. Mesmo áreas que não realizaram conferências nacionais em 2009 e 2010 tiveram programas federais que declararam o uso dessas interfaces socioestatais. Isso, como veremos, pode indicar a influência de processos de áreas correlatas, bem como que os efeitos dos processos conferenciais podem ser sentidos ao longo do tempo e não apenas nos anos de sua realização.

\section{Conferências nacionais como interfaces socioestatais}

As conferências nacionais, entendidas como "processos participativos que reúnem, com certa periodicidade, representantes do Estado e da sociedade civil para a formulação de propostas para determinada política pública” (SouzA, 2012, p. 9), podem ser consideradas interfaces socioestatais. As conferências podem ser examinadas com essa lente analítica por serem espaços intencionais de intercâmbio e conflito entre sujeitos estatais e sociais, sejam estes coletivos ou individuais. Ademais, mesmo com regulamentação específica, são convocadas por período determinado e não têm existência contínua.

Há intencionalidade no processo conferencial, tanto do ponto de vista do Estado quanto da sociedade, pois a convocação é feita pelo Poder Executivo e a adesão social é facultativa. Observadas as etapas preparatórias, em especial municipais e livres, percebe-se que o envolvimento é proposital. Afinal, os indivíduos e os grupos que se envolvem nessas atividades locais agem deliberadamente. A etapa livre, cada vez mais usada pelas conferên$\operatorname{cias}^{6}$, ressalta o caráter intencional, pois se realiza conforme a capacidade organizativa dos grupos sociais interessados.

Nas etapas preparatórias, mesmo que indivíduos possam tomar parte e não

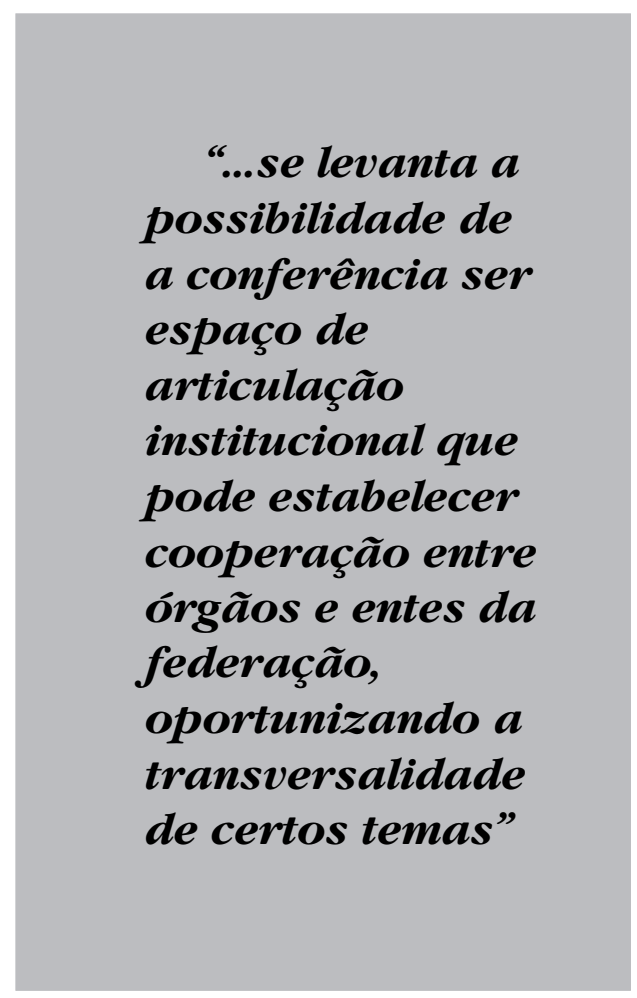

necessariamente organizações coletivas, o que se vê, em grande medida, é um processo participativo no sentido delineado, ou seja, exercício coletivo do poder político. Isso ocorre porque as conferências são realizadas em uma dinâmica deliberativa (FARIA et al., 2012). No entanto, há também conferências que possibilitam a interação individual com o Estado, em 
particular quando realizam modalidades virtuais em que as pessoas formulam propostas via internet, em plataformas especialmente desenhadas para tal. Não raro também, essas modalidades buscam fomentar o diálogo, configurando-se novamente como participação. De toda forma, individual ou coletivamente, as conferências possibilitam intercâmbio ou conflito entre Estado e sociedade.

Passadas as etapas iniciais, as conferências seguem um processo encadeado em que há escolha de representantes para as fases seguintes. No momento de escolha de representantes, existem especificações de vagas para governo e sociedade. Isso fortalece a característica de interação entre Estado e sociedade, pois o governo é reconhecido como participante do processo (TeIXEIRA et al., 2012). Nesse sentido, conferências não seriam espaços apenas de escuta de demandas, mas de intercâmbio e conflito entre representantes sociais e estatais. Seriam espaços de encontro intencional entre atores estatais e sociais, com múltiplas visões e intenções.

\section{Usos das conferências em 2009 e 2010}

Ao observar os 399 programas que declararam possuir alguma interface socioestatal, percebe-se que apenas 15\% disseram utilizar as conferências como forma de relação com a sociedade. Entre os 337 programas que não utilizaram conferências como interfaces, a maior parte é de políticas sociais e de infraestrutura e recursos nacionais, como se observa no Gráfico 1.

É possível ver que, mesmo com grande número de programas utilizando interfaces socioestatais, com a ampliação do número de conferências realizadas e com a maior visibilidade dada à participação social, ainda há baixo uso das conferências pelos programas. As conferências, embora tenham grande potencial de mobilização popular $^{7}$, não foram consideradas como forma de relação com a sociedade pela maioria dos gestores públicos responsáveis pelos programas federais realizados em 2009 e 2010. Tendo em vista que a

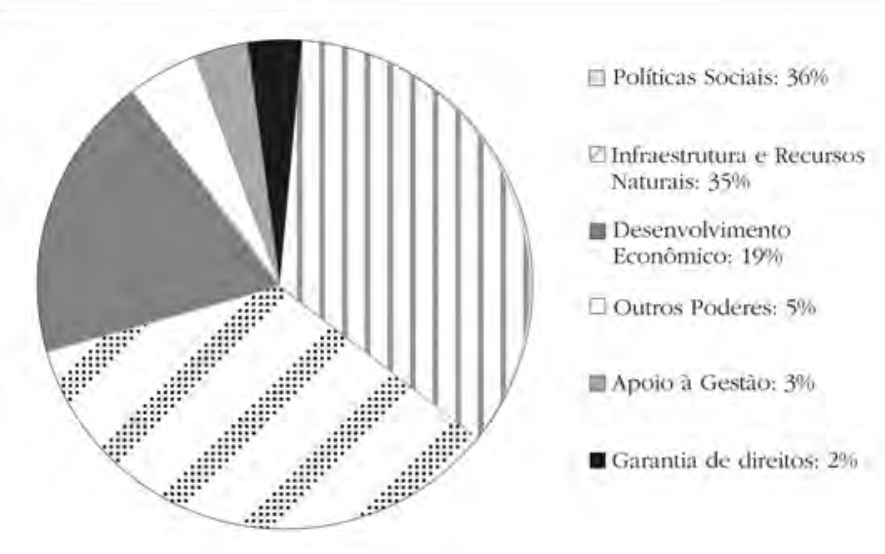

Fonte: Sigplan 2009 e 2010, elaboração própria.

Gráfico 1: Proporção de programas que não utilizaram conferências 
declaração de uso das conferências pelos programas poderia estar vinculada a ciclos mais amplos de gestão, como é o próprio PPA, cabe seguir a investigação para verificar se, em anos de formulação do plano, essa taxa de utilização seria alterada. O que pudemos perceber com os dados disponíveis é que, no período analisado, em vigência o PPA 2008-2011, houve baixo uso das conferências, inclusive se levarmos em consideração que era época de revisão do plano.

Dos 62 programas que afirmaram utilizar conferências nacionais ${ }^{8}, 12$ disseram realizar conferência, e todos os outros tipos de interface indicados no questionário de avaliação do PPA, a saber: ouvidorias, conselhos, reuniões com grupos de interesse, audiências e consultas públicas. Somente um programa (Conservação e Uso Sustentável da Biodiversidade e dos Recursos Genéticos) disse que utilizou apenas a conferência como forma de interface socioestatal.

Entre os programas que declararam utilizar conferências nacionais, $68 \%$ eram da área de políticas sociais, 13\% de desenvolvimento econômico, $11 \%$ de infraestrutura e recursos naturais e $8 \%$ de garantia de direitos. Nem programas de outros poderes, nem de apoio à gestão disseram ter realizado conferências nos anos de 2009 ou 2010. O Gráfico 2 apresenta o contraste entre o número de programas com e sem conferências nacionais.

Conforme mencionado no gráfico, é possível perceber que garantia de direitos é a área de política pública com maior proporção de programas com conferências nacionais $(41 \%)$. Em seguida, vêm os programas de políticas sociais, em que $26 \%$ do total utilizaram conferência com interface socioestatal. A área de desenvolvimento econômico contou com $11 \%$ dos

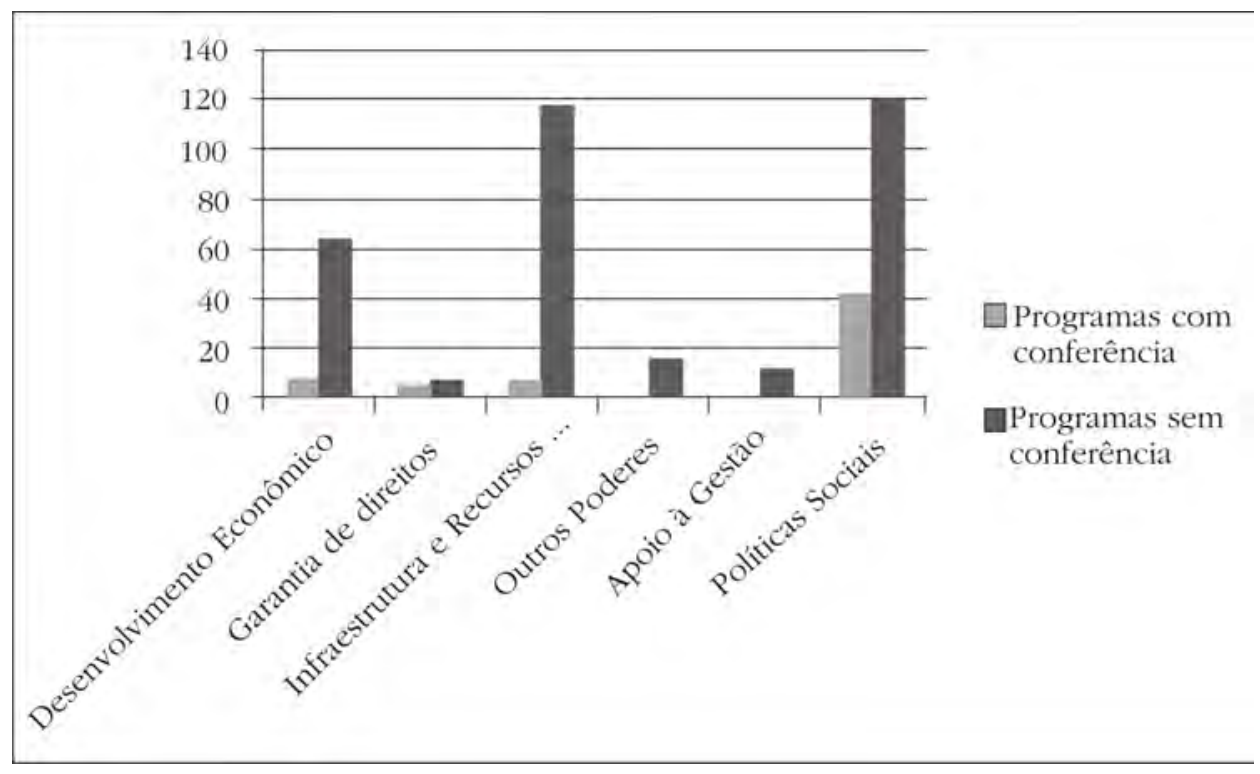

Fonte: Sigplan 2009 e 2010, elaboração própria.

\section{Gráfico 2: Programas com e sem conferências nacionais}


programas com conferências, e apenas 5\% dos programas de infraestrutura e recursos naturais utilizaram as conferências como forma de relação com a sociedade. Para comparação, é útil observar a Tabela 1, que traz a distribuição das conferências nacionais realizadas entre 2009 e 2010 por área de política.

Ao observar o Gráfico 2, verifica-se que a maior proporção de uso das conferências como interface socioestatal ocorre em programas de garantia de direitos. No entanto, no período não ocorreu nenhuma conferência relacionada a essa área, conforme indica a Tabela 1. Ao mesmo tempo, nenhum programa de apoio à gestão declara usar conferência como interface socioestatal, mesmo que no período tenha ocorrido uma conferência dessa área. Isso pode sinalizar que os gerentes de programas da área de garantia de direitos estejam considerando conferências de outras áreas como espaço de interlocução com a sociedade. Ao mesmo tempo, programas da área de apoio à gestão, ao menos os que tratam de temas afetos aos recursos humanos, parecem ignorar a realização da conferência da área, ocorrida em 2009.
Finalidades e papéis das conferências nacionais em 2009 e 2010

A constatação do baixo uso das conferências nacionais como interfaces socioestatais, as distintas proporções de utilização, a depender da área de política, e a possível consideração de conferências de outras áreas ou desconsideração das conferências da área do programa, levantam a questão sobre os papéis que esses processos podem ter adquirido nesse período. A parte que cabe a esse tipo de interface no ciclo de gestão de políticas públicas, ou seja, sua incidência na gestão é uma indagação de difícil resposta e, aqui, não é enfrentada diretamente. No entanto, podemos tecer considerações sobre as visões dos gerentes de programas federais a respeito das conferências nacionais, o que pode sinalizar potenciais e limites para a incidência de tais interfaces socioestatais.

Antes dessa consideração, cabe conhecer os objetivos declarados nos atos normativos das conferências, pois já expressam o resultado do encontro de visões de atores sociais e estatais; afinal, são definidos na comissão organizadora

Tabela 1: Distribuição de conferências nacionais por áreas de políticas

\begin{tabular}{l|c|c}
\hline Área Privada & $\begin{array}{l}\text { Número de } \\
\text { Conferências }\end{array}$ & $\mathbf{0}$ \\
\hline Apoio à gestão & 1 & 19 \\
\hline Desenvolvimento econômico & 4 & 0 \\
\hline Garantia de direitos & 0 & 9 \\
\hline Infraestrutura e recursos naturais & 2 & 0 \\
\hline Outros poderes & 0 & 67 \\
\hline Políticas sociais & 14 & $\mathbf{1 0 0}$ \\
\hline Total & $\mathbf{2 1}$ & \\
\hline
\end{tabular}

Fonte: Souza (2012), elaboração própria. 
que realiza os preparativos do processo. Nessa perspectiva, a multiplicidade de objetivos atribuídos às conferências já se destaca. Entre as conferências realizadas no período de 2003 a 2010, além de objetivos ligados à proposição de políticas públicas, foram observadas intenções de inclusão de temas na agenda pública, fortalecimento de espaços participativos e avaliação de políticas públicas.

O caráter propositivo é o que predomina nas conferências, com 44,2\% das ocorrências. Também se destacam os objetivos ligados ao agendamento (24,5\%), ou seja, aqueles que se referem à difusão de ideias e à afirmação de compromissos. Além disso, foram identificadas finalidades ligadas à ampliação ou ao fortalecimento de espaços participativos na gestão de políticas públicas, sentido apreendido em finalidades do grupo participação (17,3\%). Por fim, as conferências também se prestaram a objetivos de avaliação (14\%), focalizando ações de diagnóstico de uma situação ou avaliação de políticas (SouzA, 2012).

Para abordar as percepções dos gestores federais sobre as conferências nacionais, analisamos as justificativas dadas para o uso dessas interfaces socioestatais. Entre os 62 programas que disseram utilizar conferências nacionais, vemos distintas justificativas para o uso desse tipo de interface socioestatal. Entre as respostas dadas pelos gerentes de programas federais, identificamos possíveis papéis desempenhados pelas conferências na gestão pública. São eles:

- Acolhimento de demandas sociais conferência como espaço para receber reivindicações de representantes da sociedade. Por exemplo, "O Ministério realizou [a conferência] que recebeu representantes de todas as áreas (...) e acolheu suas reivindicações".
- Avaliação de ações governamentais - conferência como processo avaliativo da gestão pública. Por exemplo, "São realizadas conferências nacionais e estaduais, a fim de reunir o setor (...) para discussão dos entraves encontrados, de introdução de novas tecnologias, insumos, apoio governamental etc.".

- Difusão de informações - conferência como ocasião para informar a respeito de temas de interesse governamental.

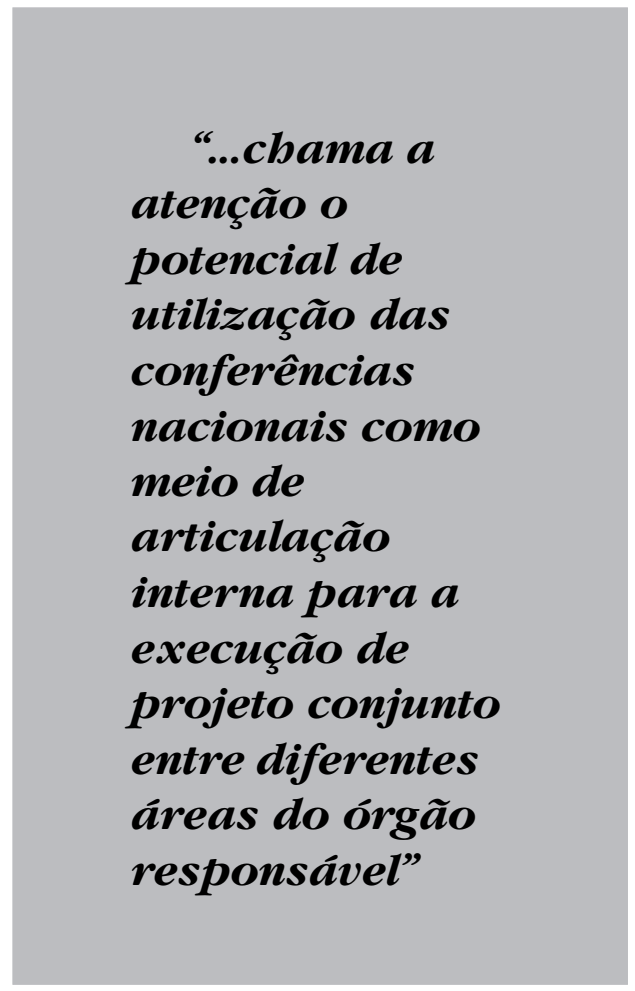

Por exemplo, "Sensibilizar a comunidade (...) para a importância da atividade (...) que contribui para a geração de renda, criação de empregos diretos e promoção da igualdade social".

- Discussão ampliada - conferência como processo de mobilização para discussão e inclusão de temas na agenda pública. Por exemplo, "O tema sugere clamor público e debates de várias políticas 
públicas que tangenciam os direitos (...), por isso sempre pautamos nas demais políticas públicas transversalmente o tema (...) a fim de viabilizar a inclusão plena, real e irrestrita no âmbito do desenvolvimento nacional".

- Formulação de diretrizes para políticas - conferência como uma etapa do ciclo de formulação de políticas públicas. Por exemplo, "As políticas (...) expressas no [plano nacional] são definidas com base nos resultados das Conferências Nacionais (...)".

- Interlocução com público-foco conferência como oportunidade de fortalecer diálogo com público destinatário da política. Por exemplo, "[O órgão] realizou a [conferência], oportunidade em que foi realizada uma plenária específica para as comunidades (...). Além da plenária, a programação da [conferência] contemplou uma mesa temática para a discussão das ações para as comunidades (...)".

- Fortalecimento da articulação federativa - conferência como oportunidade para fortalecer vínculos da União com estados e municípios. Por exemplo, "Destacam-se as conferências (...) no sentido de compartilhar a política (...) com estados e municípios, criando uma rede (...)".

- Representação institucional - conferência como possibilidade do órgão gestor de uma política se fazer representar em espaços correlatos. Por exemplo, "Destaca-se que em 2010, no âmbito do [programa], o [ministério] participou da [conferência], apoiando tanto sua organização quanto assegurando a representação deste ministério nos debates relativos à intersetorialidade entre política de assistência social e de saúde mental".

Como poderíamos esperar, há multiplicidade de papéis desempenhados pelas conferências nacionais. Observando o agrupamento em oito blocos de respostas, que vão da interlocução com público-foco à articulação federativa, passando pela avaliação de ações e pela representação institucional, sem desconsiderar o acolhimento de demandas, a discussão ampliada e a formulação de diretrizes para políticas, percebe-se a abundância de justificativas para o uso dessas interfaces. São modos de expor como os programas federais utilizam as conferências, os quais extrapolam o que seria mais esperado pelas características dessas, ou seja, o intercâmbio de informações e a formulação de propostas.

Aparentemente, os gerentes de programas identificam nas conferências oportunidades ligadas a outras fases do ciclo de gestão de políticas públicas. Não se trata, pois, de ver as conferências apenas como espaços para a recepção e negociação de demandas sociais que resultariam na formulação de políticas, mas de reconhecer outros potenciais desse tipo de interface socioestatal.

Como ocorre na pesquisa de Souza (2012), a respeito das finalidades declaradas a priori, constata-se que as conferências nacionais vão além da formulação de políticas. A posteriori, percebe-se nas justificativas dadas pelos gerentes de programas federais que estes também reconhecem as conferências para além da proposição, como espaços de agendamento, avaliação e fortalecimento da participação. Na Tabela 2, estabelece-se a correspondência entre as justificativas e os objetivos.

$\mathrm{Na}$ Tabela 2 destacam-se duas justificativas sem correspondência nas finalidades: fortalecimento da articulação federativa e representação institucional. A representação institucional foi declarada como um papel da conferência nacional para 18\% dos programas que a utilizaram como interface socioestatal. Já a articulação federativa é apontada em apenas um dos programas. 
Tabela 2: Correspondência entre justificativas e objetivos de conferências nacionais

\begin{tabular}{|c|c|}
\hline Justificativas & Objetivos \\
\hline $\begin{array}{l}\text { Difusão de informações } \\
\text { Discussão ampliada }\end{array}$ & Agendamento \\
\hline Avaliação de ações governamentais & Avaliação \\
\hline Interlocução com público-foco & Fortalecimento da participação \\
\hline $\begin{array}{l}\text { Acolhimento de demandas sociais } \\
\text { Formulação de diretrizes para políticas }\end{array}$ & Proposição \\
\hline Fortalecimento da articulação federativa & 7 \\
\hline Representação institucional & Não há correspondência \\
\hline
\end{tabular}

Fonte: Dados desta pesquisa

Ao observar quais programas utilizaram as conferências nacionais como espaço para representação institucional ou para articulação federativa, nota-se que foram apenas programas da área de políticas sociais. Pelas justificativas apresentadas, não se pode perceber se essa concentração refere-se a características das políticas, dos órgãos responsáveis por elas, ou mesmo uma visão diferenciada dos gestores daquela área temática.

O Gráfico 3 indica a distribuição das justificativas nas distintas áreas de políticas públicas. Vemos que os programas de garantia de direitos, área que conta com mais programas que utilizam conferências como interface (41\%), percebem as conferências com papéis específicos: ou as conferências são para falar com os públicos de suas ações ou para formular diretrizes para a política. Também a área de infraestrutura e recursos naturais direciona os papéis das conferências nacionais: ampliar a discussão de determinado tema e formular diretrizes para políticas.
Se o Gráfico 3, que traz a distribuição das justificativas para a utilização de conferências, é comparado com o Gráfico 4, que apresenta os objetivos das conferências, declarados a priori, veremos distribuições distintas por áreas de políticas públicas. Em especial, notaremos que as conferências da área de infraestrutura e recursos naturais declararam querer mais do que os papéis que os gestores de programas da mesma área atribuíram a essas interfaces. Para além da diferença entre o dito e o realizado, pode-se pensar sobre os diferentes entendimentos de quem promove a conferência e de quem utiliza seus resultados na gestão.

É necessário aprofundar a investigação para compreender as diferentes visões dos sujeitos envolvidos nessas interfaces. Em se tratando dos papéis atribuídos às conferências nacionais, cabe ainda considerarmos alguns aspectos revelados pelas justificativas, pois se levanta a possibilidade de a conferência ser espaço de articulação institucional que pode estabelecer cooperação entre órgãos 


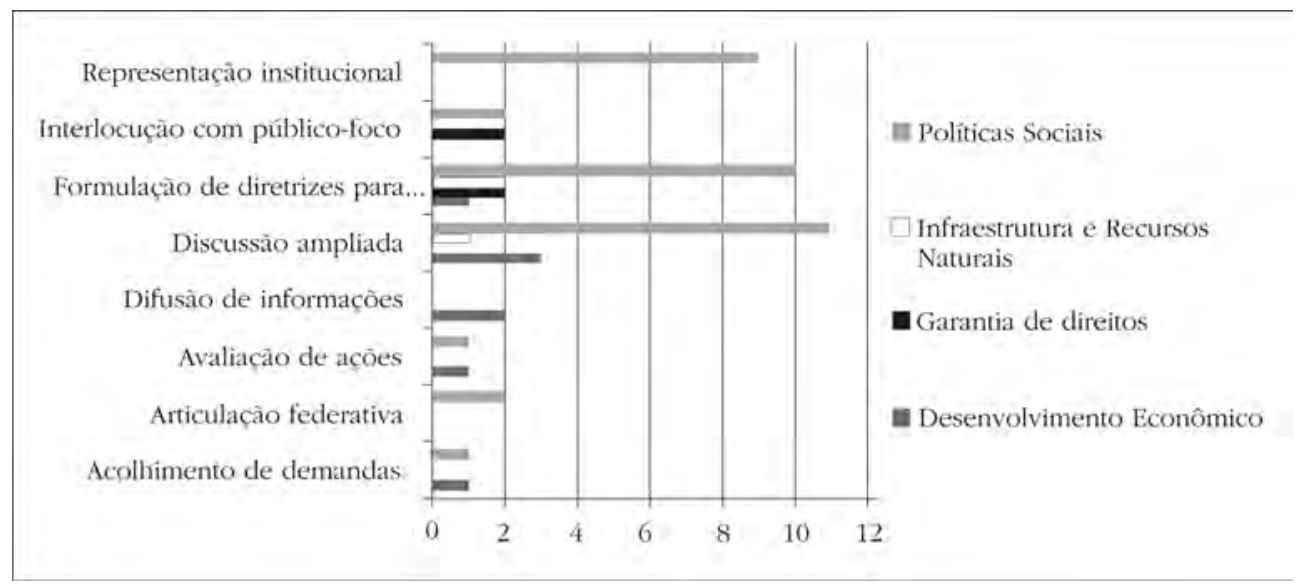

Fonte: Sigplan 2009 e 2010, elaboração própria.

Gráfico 3: Justificativas para utilização de conferências nacionais por área de política

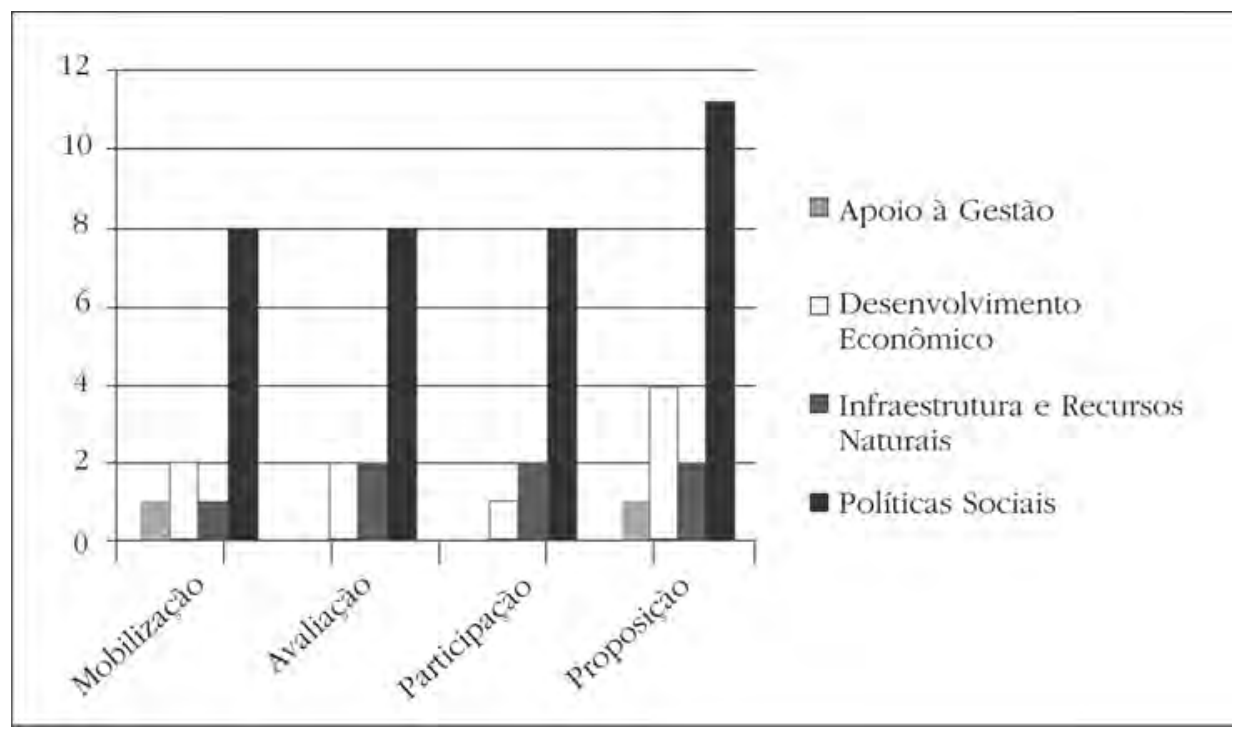

Fonte: SouZA, 2012, elaboração própria.

Gráfico 4: Objetivos de conferências nacionais por área de política 
e entes da federação, oportunizando a transversalidade de certos temas.

A ideia de representação institucional, agrupamento aqui ressaltado pela novidade indicada na pesquisa sobre conferências, também pode sinalizar que as conferências são espaços de cooperação no próprio órgão realizador. Vê-se isso na seguinte justificativa:

"[A unidade administrativa] enviou servidores para atuarem em diversas dessas conferências [municipais e estaduais], e para participarem do Comitê Executivo Nacional que preparou a conferência. Representantes [do órgão] integraram também o Grupo de Trabalho responsável pela sistematização do caderno de propostas da conferência.".

Há nessa narrativa a sinalização de que a unidade administrativa responsável pelo programa se envolveu na preparação e na realização da conferência. Embora se saiba que as conferências são realizadas por uma área do ministério, em colaboração com o conselho nacional, em alguns casos há dificuldades de envolvimento de outros setores do próprio ministério. Por isso, chama a atenção o potencial de utilização das conferências nacionais como meio de articulação interna para a execução de projeto conjunto entre diferentes áreas do órgão responsável. Isso pode, inclusive, ter consequências na incidência das conferências, pois os técnicos envolvidos no processo podem contribuir com o encaminhamento dos resultados.

Vale ressaltar que também couberam na categoria representação institucional as respostas mais evasivas como "participação na [conferência]" ou "participação em algumas conferências municipais e estaduais". A ideia de representação institucional, apenas como comparecimento, também pode ser percebida quando se analisa as respostas dadas pelos gestores. Isso indica que as conferências nacionais podem estar na rotina de eventos em que gestores públicos necessitam comparecer, sem que isso, necessariamente, sinalize qualquer envolvimento nas discussões que possa diretamente fazer pontes com as ações do programa federal.

\section{Considerações finais}

A noção de interface socioestatal possibilita o reconhecimento das distintas perspectivas de sujeitos sociais e estatais sobre as relações entre Estado e sociedade. O olhar para as conferências, a partir da perspectiva dos agentes do Estado, revela sentidos e usos peculiares atribuídos a essas interfaces. Conhecer a visão desses atores a respeito das conferências nacionais foi o intento deste trabalho. Percebe-se que gestores públicos federais assinalam que as conferências, como interfaces socioestatais, desempenham múltiplos papéis.

Além das funções de proposição de políticas e de intercâmbio informacional, verifica-se que as conferências nacionais tiveram como finalidades o agendamento, a avaliação e o fortalecimento da participação. Além da confirmação de pesquisas anteriores, os resultados aqui apresentados revelam que as conferências nacionais são vistas pelos gestores também como oportunidade de representação institucional. Nesse sentido, pode-se considerar que os gerentes de programas identificam nas conferências outros potenciais desse tipo de interface socioestatal, a saber: articulação interinstitucional e articulação interna.

Constata-se que esse tipo de interface pode, então, oportunizar cooperação entre 
órgãos e também ampliar vínculos no próprio órgão responsável pela conferência nacional. O expressivo número de programas $(18 \%$ dos que utilizaram conferências nacionais) que sinalizou que essa interface cumpre papel de representação institucional pode indicar, inclusive, que os programas recebem inputs de diferentes conferências. Isso foi percebido também quando gerentes de programas afirmaram ter utilizado conferências, mesmo que em sua área de política não tenham sido realizados processos conferenciais no período. Observa-se, assim, que uma conferência nacional pode ser utilizada como interface socioestatal por diferentes programas. Esse é o potencial que a noção de representação institucional nos revela. Ao mesmo tempo, cabe perceber que existem limites em tal ideia, pois alguns gestores sinalizam que as conferências nacionais são parte de atribuições rotineiras, sem impacto direto na gestão do programa. Isso pode ser pensado quando as respostas revelam que a conferência é mais um evento em que se precisa comparecer.

Mesmo com o grande uso de interfaces socioestatais nos programas federais e com a ampliação da quantidade de pessoas envolvidas e de temas em pauta em conferências nacionais, esse tipo de interface tem sido pouco utilizado pelos programas, como meio de relação com a sociedade (apenas $15 \%$ dos programas federais declararam utilizá-la). Por um lado, os gestores públicos podem considerar outras interfaces socioestatais como mais adequadas à relação com a sociedade. Por outro lado, as conferências nacionais podem ainda não ter sido compreendidas e utilizadas. Ambas as possibilidades indicam desafios na gestão das interfaces socioestatais.

Conhecendo a multiplicidade de entendimentos a respeito das conferências nacionais, caberá seguir na investigação sobre a percepção dos gestores federais a respeito dos desafios da gestão pública participativa. Considerando o modo de organização das conferências, seus usos, os distintos objetivos declarados a priori e os diversos papéis atribuídos a posteriori, podemos construir bases para investigar os efeitos de tais interfaces na gestão pública. A partir dos resultados do trabalho aqui apresentado, fortalecemos a hipótese a ser investigada: o grau de incidência das interfaces socioestatais na gestão das políticas também é função da visão do gestor sobre a contribuição destas para suas atividades gerenciais.

(Artigo recebido em agosto de 2012. Versão final em dezembro de 2012).

\section{Notas}

1 Em alguma medida, a noção de interface retoma insights já presentes no debate sobre instituições participativas no Brasil, como o conceito de instituições híbridas (AVRITZER \& PEREIRA, 2005).

2 Hevia e Vera (2010, p. 64-65) propõem alguns tipos ideais de interfaces: de contribuição, de transparência, comunicativa, mandatória, de transferência e cogestionária. A tipologia é útil para o entendimento, mas é necessário ressaltar que os próprios autores reconhecem que há imbricação dos tipos na experiência empírica. 
3 Agradecemos à equipe da Secretaria de Planejamento e Investimentos Estratégicos do Ministério do Planejamento, Orçamento e Gestão pelo apoio à pesquisa e acesso aos dados. Aproveitamos para agradecer a Alexander Vaz pela contribuição fundamental no tratamento das informações.

4 Foram 240 programas em 2009 e 194 em 2010; deste total, a maior parte refere-se a programas de políticas sociais $(39 \%)$ e de infraestrutura e recursos naturais $(31 \%)$, sendo também expressiva a proporção de programas de desenvolvimento econômico (19\%), e com menor proporção as áreas de garantia de direitos (3\%), apoio à gestão (4\%) e outros poderes (4\%). Entre os 434 programas, apenas 9\% não contaram com alguma interface socioestatal.

5 Não foram encontrados os objetivos das seguintes conferências: $1^{\text {a }}$ de Aprendizagem Profissional; $1^{a}$ de Aquicultura e Pesca; $3^{\text {a }}$ de Arranjos Produtivos Locais; $3^{\text {a }}$ de Saúde Bucal; $8^{a}$ e $10^{a}$ dos Direitos Humanos.

6 Teixeira et al. (2012, p. 27) indicam que das 74 conferências realizadas entre 2003 e 2010, seis contaram com etapas livres.

7 De acordo com pesquisa do Prodep/Vox Populi, mais de 40\% da população brasileira ouviu falar das conferências, sendo que $6,5 \%$ da população participou nas diversas etapas (Avritzer, 2012, p. 12).

8 Nos anos de 2009 e 2010, foram realizadas 21 conferências. Foram elas: $1^{\text {a }}$ de Comunicação; $1^{a}$ de Defesa Civil e Assistência Humanitária; $1^{a}$ de Educação; $1^{a}$ de Educação Escolar Indígena; $1^{\text {a }}$ de Saúde Ambiental; $1^{\text {a }}$ de Segurança Pública; $1^{\text {a }}$ de Recursos Humanos da Administração Pública Federal; $2^{\mathrm{a}}$ das Comunidades Brasileiras no Exterior; $2^{\mathrm{a}}$ de Cultura; $2^{\mathrm{a}}$ dos Direitos da Pessoa Idosa; $2^{a}$ de Economia Solidária; $3^{a}$ das Comunidades Brasileiras no Exterior; $3^{a}$ de Aquicultura e Pesca; $3^{a}$ do Esporte; $3^{a}$ Infanto-Juvenil pelo Meio Ambiente; $4^{a}$ de Arranjos Produtivos Locais; $4^{a}$ das Cidades; $4^{a}$ de Ciência Tecnologia e Inovação; $4^{a}$ de Saúde Mental; $7^{a}$ de Assistência Social; $8^{\text {a }}$ dos Direitos da Criança e do Adolescente.

\section{Referências bibliográficas}

Abers, Rebecca; Serafim, Lizandra; TAtAgiba, Luciana. Novas relações Estado-sociedade no governo federal brasileiro: uma visão desde um Estado heterogêneo. Trabalho apresentado no GT Controles democráticos e legitimidade do $35^{\circ}$ Encontro Anual da ANPOCS, 2011, Caxambu.

Alencar, Joana Luiza Oliveira; Pires, Roberto Rocha Coelho; Fonseca, Igor Ferraz; Cruxên, Isadora Araújo; Ribeiro, Uriella Coelho. Participação social e desigualdade nos conselhos nacionais. Trabalho apresentado no GT Novas Arenas de Participação do Simpósıo Nacional Sobre Democracia E Desigualdades, Brasília, 2012.

Avelar, Lúcia. Participação Política. In: Avelar, Lúcia. \& Cintra, Antônio Octávio (orgs.) Sistema político brasileiro: uma introdução. 2 ed .Rio de Janeiro: Fundação KonradAdenauer-Stiftung; São Paulo: Fundação Unesp, 2007.

Avritzer, Leonardo. (org.) Sociedade Civile democratizaçãa. Belo Horizonte: Del Rey, 1994. 
. A moralidade da democracia. São Paulo/Belo Horizonte: Perspectiva/UFMG, 1996.

. Democracy and the public space in Latin America. Princeton: Princeton, 2002. . Conferências nacionais: ampliando e redefinindo os padrões de participação social no Brasil. Texto para discussão 1739. Rio de Janeiro: IPEA, 2012.

Avritzer, Leonardo \& Pereira, Maria de Lourdes Dolabela. Democracia, participação e instituições híbridas. In: Teoria \& Sociedade. Número especial. Março de 2005.

Faria, Cláudia Feres; Lins, Isabella L.; Lobão, Evelyn R.; Cardoso, João Antônio P.; Petineld, Viviane. Conferências Locais, Distritais e Municipais de Saúde: mudança de escala e formação de um sistema participativo, representativo e deliberativo de políticas públicas. Texto para discussão 1727. Rio de Janeiro: IPEA, 2012.

Hevia, Felipe \& Vera, Ernesto Isunza. La perspectiva de interfaz aplicada a las relaciones sociedad civil-Estado en México. In: OlverA, Alberto J. (coord.) La democratización frustrada. Limitaciones institucionales y colonización política de las instituciones garantes de derechos y de participación ciudadana en México. México: CIESAS, Universidad Veracruzana, 2010.

Lavalle, Adrian Gurza. Após a participação: nota introdutória. Lua Nova, São Paulo, 84: 13-23, 2011.

Lavalle, Adrian Gurza. \& Vera, Ernesto Isunza. Precisiones conceptuales para el debate contemporáneo sobre la innovación democrática: participación, controles sociales y representación. In: LaVAlle, Adrian Gurza. \& VERA, Ernesto Isunza. (coord.) La innovación democrática em América Latina. Tramas y nudos de la representación, la participación y el control social. México: CIESAS, Universidad Veracruzana, 2010.

Pateman, Carole. Participação e teoria democrática. Rio de Janeiro: Paz e Terra, 1992.

PIREs, Roberto Rocha Coelho [org.] Efetividade das instituições participativas no Brasil: estratégias de avaliação. Brasília: Ipea, 2011.

Pires, Roberto; VAz, Alexander. Participação social como método de governo? Um mapeamento das "interfaces socioestatais" nos programas federais. Texto para discussão 1707. Rio de Janeiro: IPEA, 2012.

Santos, Boaventura de Sousa. \& Avritzer, Leonardo. Para Ampliar o Cânone Democrático. In: Democratizar a Democracia. Boaventura de Sousa Santos. (org.) Rio de Janeiro: Civilização Brasileira, 2002.

Souza, Clóvis Henrique Leite de. A que vieram as conferências nacionais? Uma análise dos objetivos dos processos realizados entre 2003 e 2010. Texto para discussão 1718. Rio de Janeiro: IPEA, 2012.

Teixeira, Ana Claudia Chaves. Souza, Clóvis Henrique Leite de. Lima, Paula Pompeu Fiuza. Arquitetura da participação no Brasil: uma leitura das representações políticas em espaços participativos nacionais. Texto para discussão 1735. Rio de Janeiro: IPEA, 2012. VERA, Ernesto Isunza. Interfaces socioestatais, prestação de contas e projetos políticos no contexto da transição política mexicana. In: Dagnino, Evelina. Olvera, Alberto J. \& Panfichi, Aldo. A disputa pela construção democrática na América Latina. São Paulo: Paz e Terra, 2006. 


\section{Resumo - Resumen - Abstract}

\section{Conferências nacionais como interfaces socioestatais: seus usos e papéis na pers-} pectiva de gestores federais

Clóvis Henrique Leite de Soura e Roberto Rocha Coelho Pires

O estudo enfoca as conferências nacionais promovidas ao longo da última década pelo governo federal, como uma forma de interface entre Estado e sociedade. São utilizados dados oriundos de registros administrativos de avaliação de todos os programas federais que compõem o Plano Plurianual e informações contidas em atos normativos de conferências nacionais. Os resultados das análises revelam os padrões de distribuição das conferências nas diversas áreas de políticas públicas e as percepções de gestores públicos sobre os papéis que tais processos participativos vêm desempenhando na execução de programas federais. O conjunto de dados e análises sugere novos parâmetros para a reflexão sobre instituições participativas, em especial o reconhecimento da perspectiva dos atores estatais como elemento central para a compreensão das formas de relação entre Estado e sociedade, na efetivação da gestão pública participativa.

Palavras-chave: conferências; interfaces socioestatais; participação

Conferencias nacionales como interfaces socioestatales: sus usos y papeles en la perspectiva de los gestores federales

Clóvis Henrique Leite de Souza y Roberto Rocha Coelho Pires

El estudio se centra en las conferencias nacionales promovidas en la última década por el gobierno federal como una forma de relación entre Estado y sociedad. Los autores utilizan datos procedentes de registros administrativos para evaluar todos los programas federales que conforman el Plan Plurianual y la información contenida en los actos normativos de las conferencias nacionales. Los resultados del análisis muestran la distribución de las conferencias en las diversas áreas de políticas públicas, las percepciones de los gerentes públicos acerca de las funciones que estos procesos de participación han jugado en la ejecución de los programas federales. El conjunto de datos y análisis sugiere nuevos parámetros para el debate sobre las instituciones participativas, en particular el reconocimiento de la perspectiva de los actores estatales como central para entender el tipo de relación entre el Estado y la sociedad, para la efectuación de la gestión pública participativa.

Palabras claves: conferencias; interfaces socioestatales; participación

National conferences as state-society interfaces: their uses and roles from the point of view of federal managers

\section{Clóvis Henrique Leite de Souza and Roberto Rocha Coelho Pires}

The study focuses on national conferences promoted in the last decade by the federal government as a form of relationship between State and society. The authors use data from administrative records to evaluate all federal programs that integrate the Multi-Year Plan and the information contained in legislative acts of the national conferences. The analysis shows conferences' distribution in areas of public policy, public managers' perceptions about the roles that these participatory processes have played in implementing federal programs. The set of data and analysis suggests new parameters for the debate on participatory institutions, in particular the recognition of the perspective of state actors as central to understanding the type of relationship between State and society for effective participatory governance.

Keywords: conferences; state society interaction; participation 
Clóvis Henrique Leite de Souza

Mestre em Ciência Política pela Universidade de Brasília e Assistente de Pesquisa no Instituto de Pesquisa Econômica Aplicada (Ipea).Contato: clovis.souza@ipea.gov.br

Roberto Rocha Coelho Pires

Doutor em Políticas Públicas pelo Massachusetts Institute of Technology e Técnico de Planejamento e Pesquisa no Instituto de Pesquisa Econômica Aplicada (Ipea). Contato: roberto.pires@ipea.gov.br 